\title{
PENGARUH JENIS KEMASAN DAN LAMA PENYIMPANAN TERHADAP KARAKTERISTIK MUTU BUAH HARIMONTING ( Rhodomytus tomentosa)
}

\{EFFECT OF PACKAGING AND DURATION STORAGE OF CHARACTERISTICS QUALITY HARIMONTING FRUIT ((Rhodomytus tomentos)\}

\author{
Hotman Manurung1dan Rosnawyta Simanjuntak ${ }^{1}$ \\ 1Program Studi Teknologi Hasil Pertanian, \\ Fakultas Pertanian Universitas HKBP Nommensen Medan \\ hotman.manurung@uhn.ac.id
}

\begin{abstract}
Abstrac
The purpose of this study was to determine the effect of the type of packaging on characteristics of quality of the karimunting fruits during storage. The experimental design used was completely randomized design with two factors. The first factor was type of packaging with 2 levels, namely polyethylene (PE) plastic box and wrapping packaging. The second factor was storage duration (L): 0, 1, 2, 3, and 4 days. The study was conducted with 3 replications. Parameters observed were $\mathrm{IC}_{50}$, weight loss, texture, color, total soluble solid, and color preference. The results showed that the longer storage the higher $\mathrm{IC}_{50}$ for both $\mathrm{PE}$ and wrapping. The highest IC50 (97.04 ppm) was in the storage of day 4 with PE plastic packaging. The reduction of weight was higher with plastic packaging $(7.40 \%)$ compared with wrapping packaging $(4.80 \%)$. Karimunting packed with PE plastic produced higher total solid soluble (TSS) (7.60brix) compared with wrapping storage (6.20brix)

Keywords: Karimunting, antioxidant, weight loss, vitamin C.
\end{abstract}

\section{A.PENDAHULUAN}

Bagi masyarakat Batak, hutan tidak hanya menjadi sumber pangan, sandang, energi dan obat-obatan dan tempat tinggi namun juga mempengaruhi nilai dan budaya mereka. Sebagai sumber pangan, selain berladang masyarakat Batak mencari berbagai buah di hutan. buah hutan yang sering diambil dari hutan oleh Suku Batak Toba diantaranya Rau, Sotul, Harimonting, Sanduduk, Pirdot, Mobe, Hambirbir, danHaheat ( Situmorang dan Harianja, 2014). Menurut Harianja (2016) terdapat 10 jenis buahbuahan hutan yang sudah mempunyai permintaan pada masyarakat Batak Toba, yakni Sihim, Riuk-riuk, Rambutan hutan, Tungirtungir, Ruham, Handis, Hopong, Kapundung, Mobe, Barangan, Habo, Pining Bodat, Harimonting, Bosi-Bosi, Cempedak Hutan, dan Sotul, dengan pemanfaatan untuk buah segar, buah olahan, bumbu masak maupun untuk obat-obatan. Hasil uji aktivitas antioksi dan biji dan daging buah karamunting menunjukkan adanya potensi antioksidan dengan nilai IC50 berturut-turut sebesar
99,52 ppm, dan 618,98 ppm (Sari, et al.,2018).

Harimonting seperti buah-buahan lainnya merupakan materi yang masih melakukan aktivitas metabolisme walaupun telah dipanen. Aktivitas metabolism setelah panen cenderung menurunkan mutu buah-buahan. Untuk menghindari kerusakan ini dapat diupayakan dengan cara penanganan pasca panen dan pengemasan yang dapat memperpanjang masa simpan buah (Iflah et al., 2012., Naibaho, 2014).

Penelitian ini bertujuan untuk mengetahui pengaruh jenis kemasan terhadap karateristik mutu buah harimonting selama penyimpanan

\section{B.METODOLOGI \\ Tempat dan Waktu Penelitian}

Penelitian dilaksanakan di

Laboratorium Pengolahan Fakultas Pertanian Universitas HKBP Nommensen, sedangkan analisis mutu dilaksanakan di Laboratorium Ilmu Pangan Universitas Sumatera Utara Medan dengan lama penelitian 3 (tiga) bulan. 


\section{Bahan dan Alat}

Bahan yang digunakan adalah : Buah harimonting yang diperoleh dari pengumpul harimonting di Desa Marom Kecamatan Uluan. Kemasan kotak plastik jenis PE (Polyethilen) dan kemasan wrapping. Alat yang digunakan adalah: Blender, baskom, neraca analitik, gelas ukur, spektrometer, kromatometer , tekstur meter dan oven.

\section{Rancangan Penelitian}

Penelitian dilakukan dengan metode ekperimental dengan Rancangan yang digunakan adalah Rancangan Acak Lengkap Faktorial (RALF) dengan 2 perlakuan yaitu: 1 . Jenis kemasan terdiri dari 2 taraf yaitu plastic kotak PE dan kemasan wrapping, 2. Lama penyimpanan (L): 0, 1, 2, 3, dan 4 hari. Penelitian dilakukan dengan 3 ulangan sehingga total kombinasi perlakuan 15 unit.

\section{Pelaksanaan Penelitian:}

Buah harimonting yang telah ranum (berwarna merah ungu) disortir secara manual berdasarkan kesamaan ukuran, tekstur dan warna sehingga diperoleh harimonting yang seragam. dibersihkan dengan air bersih dari kotoran misalnya pasir dan tanah yang masih lengket pada buah harimonting. Kemudian dikering anginkan sampai tidak ada air yang menetes dan permukaan buah harimonting telah kering. Harimonting yang telah kering ditimbang kira -kira 150 gr lalu dikemas sesuai dengan perlakuan pertma dan disimpan selama sesuai perlakuan ke 2 pada suhu kamar. Lalu dilakukan analisis mutu.

Parameter mutu yang dianalisis:

1. Daya antioksidan (Metode DPPH, Ramadan, M. F dan Moersel, J. T. 2006).

2. Kadar gula (Sudarmadji, S., Bambang. H, dan Suhardi. 1987)

3. Tekstur(Sudarmadji, S., Bambang. H, dan Suhardi. 1987)

4. Warna(Sudarmadji, S., Bambang. H, dan Suhardi. 1987)

5. Total soluble soilid (Sudarmadji, S., Bambang. H, dan Suhardi. 1987)

6. Uji kesukaan warna (Soekarto, S.T. 1985)

\section{HASIL DAN PEMBAHASAN}

Secara umum dapat dikatakan
bahwa jenis kemasan dan lama penyimpanan mempengaruhi fisikokimia buah harimonting seperti telihat pada Tabel 1 dan Tabel 2 di bawah ini.

Tabel 1. Pengaruh Jenis kemamasan Terhadap Fisikokimia Buah Harimonting

\begin{tabular}{llllll}
\hline $\begin{array}{l}\text { Ienis } \\
\text { Kemasan }\end{array}$ & $\begin{array}{l}\mathrm{IC}_{50} \\
\text { (ppm) }\end{array}$ & $\begin{array}{l}\text { Susut } \\
\text { bohot }\end{array}$ & $\begin{array}{l}\text { Padatan } \\
\text { terlarut } \\
\text { (brix) }\end{array}$ & $\begin{array}{l}\text { Wjii } \\
\text { Kesukaan } \\
\text { warna }\end{array}$ & $\begin{array}{l}\text { Kandungan } \\
\text { VitC } \\
\text { (mg/100g) }\end{array}$ \\
\hline Plattik & $88,04 \pm 0,17$ & $7,40 \pm 0,78$ & $7,40 \pm 0,56$ & $3,07 \pm 0,26$ & $35,27 \pm 8,91$ \\
Wrapping & $73,54 \pm 0,84$ & $4,80 \pm 0,09$ & $6,20 \pm 0,28$ & $3,14 \pm 0,57$ & $31,29 \pm 7,77$ \\
\hline
\end{tabular}

Tabel 2. Pengaruh Lama Penyimpanan terhadap Fisikokimia Buah Harimonting

\begin{tabular}{lccccc}
\hline $\begin{array}{l}\text { Lama } \\
\begin{array}{l}\text { Penximpanan } \\
\text { (hari) }\end{array}\end{array}$ & $\begin{array}{c}\mathrm{IC}_{50} \\
\text { (ppm) }\end{array}$ & $\begin{array}{c}\text { Susut } \\
\text { bohot } \\
(\%)\end{array}$ & $\begin{array}{c}\text { Padatan } \\
\text { terlarut } \\
\text { (Brix) }\end{array}$ & $\begin{array}{c}\text { Lji } \\
\text { kesukaan } \\
\text { warna }\end{array}$ & $\begin{array}{c}\text { Kandungan } \\
\text { Vit.C } \\
\text { (mg/100g) }\end{array}$ \\
\hline $\mathbf{0}$ & $65,17 \pm 2,63$ & $0,0 \pm 0.00$ & $8,0 \pm 1,14$ & $2,97 \pm 0,32$ & $42,94 \pm 7,55$ \\
1 & $74,42 \pm 7,01$ & $4,16 \pm 2,04$ & $8,25 \pm 0,95$ & $3,33 \pm 0,20$ & $39,96 \pm 7,09$ \\
2 & $79,73 \pm 8,44$ & $5,90 \pm 2,67$ & $6,25 \pm 0,95$ & $2,53 \pm 0,44$ & $31,78 \pm 2,94$ \\
3 & $89,95 \pm 2,34$ & $8,99 \pm 2,17$ & $5,75 \pm 0,50$ & $3,33 \pm 0,26$ & $32,03 \pm 4,82$ \\
4 & $94,99 \pm 2,13$ & $11,48 \pm 2,10$ & $5,25 \pm 0,95$ & $3,25 \pm 0,38$ & $22,22 \pm 1,77$ \\
\hline
\end{tabular}

Pada Tabel 1 terlihat bahwa nilai dari daya antioksidan, susut bobot, padatan terlarut, dan vit.C pada harimonting yang dikemas dengan plastik lebih tinggi dibanding dengan harimonting yang dikemas dengan wrapping. Sebaliknya nilai uji warna lebih tinggi pada harimonting yang dikemas dengan wrapping dibandingkan pada kemasan plastik. Sementara itu pada Tabel 2 terlihat bahwa semakin lama penyimpanan mengakibatkan daya antioksidan (IC50), susut bobot, warna semakin meningkat, sedangkan padatan terlarut dan Vit.C sebaliknya semakin menurun.

Untuk mengetahui pengaruh jenis kemasan dan lama penyimpanan maka dilakukan uji sidik ragam dan bila pengaruhnya nyata maka dilanjutkan dengan uji Duncan.

\section{Pengaruh Interaksi lama Penyimpanan dan jenis kemasan terhadap antioksidan ( IC $\left._{50}\right)$.}

Adapun pengaruh interaksi lama penyimpanan dan jenis kemasan terhadap antioksidan (IC50), serta lamanya penyimpanan dan jenis kemasan memberi pengaruh interaksi sangat nya terhadap IC50 seperti yang terlihat pada tabel 3 .

Pada Tabel 3 terlihat bahwa semakin lama harimonting disimpan IC50 semakin tinggi baik yang menggunakan plastic PE maupun yang menggunakan wrapping. IC $\mathrm{I}_{50}$ tertinggi $(97,04 \mathrm{ppm})$ terlihat pada perlakuan penyimpanan 
selama hari ke 4 dan kemasan plastik, dan terendah pada penyimpanan 0 hari baik pada kemasan plastik dan kemasan wrapping. Semakin tinggi nilai $\mathrm{IC}_{50}$ berarti daya antioksidannya menurun. Hai ini menunjukkan bahwa selama penyimpanan daya antioksidan buah harimonting menurun terutama pada kemasan plastik.

Tabel 3. Pengaruh interaksi lama penyimpanan dan jenis kemasan terhadap $\mathrm{IC}_{50}$.

\begin{tabular}{|c|c|c|c|c|c|}
\hline \multirow{2}{*}{$\begin{array}{l}\text { Jenis } \\
\text { Kemasan }\end{array}$} & \multicolumn{5}{|c|}{ Lama Penvimpanan (hari) } \\
\hline & 0 & 1 & 2 & 3 & 4 \\
\hline Plastilk & 58.94 & $81,45^{c}$ & $88.14^{4}$ & $91.94^{\omega}$ & $97,04^{\circ}$ \\
\hline Wrapping & 48.08 & 67,38 & $71,32^{b}$ & $87,96^{d}$ & $92,94^{\mathrm{w}}$ \\
\hline
\end{tabular}

Namun demikian buah harimonting termasuk sebagai sumber antioksidan kuat baik saat disimpan dengan kemasan plastic atau wrapping selama 4 hari. Senyawa dikatakan sebagai antioksidan sangat kuat jika nilai $\mathrm{IC}_{50}$ kurang dari 50 ppm, antioksidan kuat untuk $\mathrm{IC}_{50}$ bernilai 50 - 100 ppm, antioksidan sedang jika IC 50 bernilai 100 - 150 ppm dan antioksidan lemah jika IC $_{50}$ bernilai 151 - 200 ppm (Mardawati et al., 2008). Nilai $\mathrm{IC}_{50}$ (konsentrasi sampel uji yang mampu meredam radikal bebas sebesar 50\%) digunakan sebagai parameter untuk menentukan aktivitas antioksidan sampel uji (Prakash, 2001). Menurut sari., et al (2018) buah harimonting mengandung senyawa Flavonoid, fenolik dan Saponin yang berfungsi sebagai antioksidan.

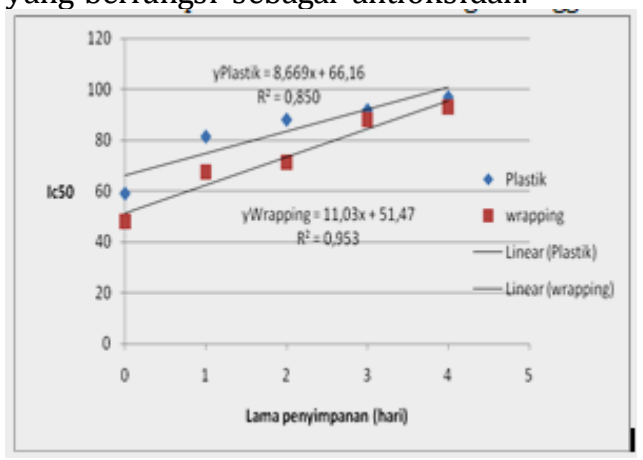

Gambar 1. Hubungan lama penyimpanan dengan daya antioksidn ( $\mathrm{IC}_{50}$ )

Peningkatan $\quad \mathrm{IC}_{50}$ selama penyimpanan baik pada kemasan plastik maupun pada wrapping mengikuti garis linier seperti terlihat pada Gambar 1. Peningkatan $\mathrm{IC}_{50}$ ini kemungkinan disebabkan terjadinya perubahan komposisi buah karumonting sehingga srtruktur flavonoid, fenolik dan saponin ikut berubah.

\section{Pengaruh lama penyimpanan dan jenis kemasan terhadap susut bobot (\%) harimonting.}

Lama penyimpanan dan jenis kemasan memberi pengaruh nyata $(p>0,05)$ terhadap susut bobot seperti terlihat pada Tabel 4

Tabel 4. Pengaruh lama penyimpanan dan jenis kemasan terhadap Susut bobot (\%) harimonting.

\begin{tabular}{|c|c|c|c|c|c|c|}
\hline \multirow{2}{*}{$\begin{array}{l}\text { Jenis } \\
\text { kemasand }\end{array}$} & \multicolumn{5}{|c|}{ Lamapenyimpanan } & \multirow[t]{2}{*}{ Ratadon } \\
\hline & 0 & 1 & 2 & 3 & 4 & \\
\hline Plastik PE & 0.00 & 5.27 & 7,39 & 11.06 & 13,30 & $7,40^{\circ}$ \\
\hline Wrapping & 0.00 & 3.06 & 4.40 & 6.92 & 9,66 & $4.80^{\circ}$ \\
\hline Ratadn & $0.00^{1}$ & 4.16 & $5,90^{\circ}$ & 8.99 & $11,48^{\circ}$ & \\
\hline
\end{tabular}

Pada Tabel 4 terlihat bahwa selama proses penyimpanan susut bobot meningkat dari $0,00 \%$ pada hari ke 0 menjadi $11,48 \%$ pada hari ke 4 . Peningkatan susut bobot selama penyimpanan disebabkan selama penyimpanan buah harimonting melakukan proses respirasi yaitu menguapkan air menjadi uap. Perubahan air harimonting menjadi uap merupakan fenomena alam dan mengikuti sifat bahan yang akan mengalami penguapan air bila kadar air bahan lebih tinggi dibandingkan $\mathrm{Rh}$ udara tempat penyimpanan bahan.

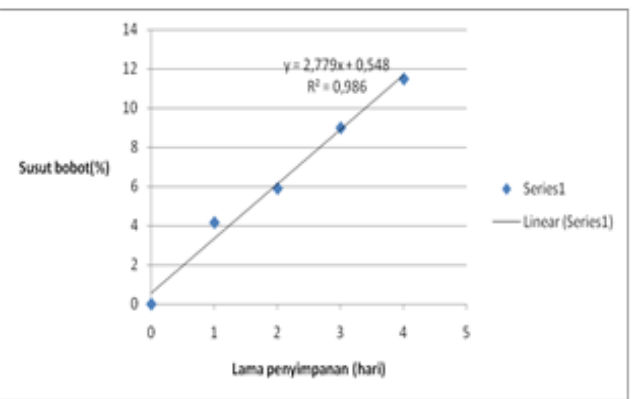

Gambar 2. Hubungan lama penyimpanan dengan susut bobot (\%)

Peningkatan susut bobot buah harimoting selama penyimpanan mengikuti garis regresi linier seperti terlihat pada Gambar 2

Pada Tabel 4 terlihat bahwa susut bobot pada penyimpanan dengan kemasan plastik lebih tinggi $(7,40 \%)$ dibandingkan dengan kemasan wrapping (4,80\%). Hal ini disebabkan kemasan plastik tidak tertutup rapat sehingga 
proses penguapan lebih tinggi dibandingkan pada kemasan wrapping.

Pengaruh lama penyimpanan dan jenis kemasan terhadap total padatan (TTS) terlarut (Brix) harimonting.

Lama penyimpanan dan jenis kemasan memberi pengaruh nyata ( $>0,05)$ terhadap total padatan terlarut seperti terlihat pada Tabel 5 .

Tabel 5. Pengaruh lama penyimpanan dan jenis kemasan terhadap total padatan terlarut (brix) harimonting

\begin{tabular}{|c|c|c|c|c|c|c|c|}
\hline \multirow{2}{*}{$\begin{array}{c}\text { Jenis } \\
\text { kemasan }\end{array}$} & \multicolumn{5}{|c|}{ Lama Penyimapanan (hari) } & \multirow[b]{2}{*}{ RATAAN } & \multirow{2}{*}{ Fhit } \\
\hline & 0 & 1 & 2 & 3 & 4 & & \\
\hline Plastilk & 9.00 & 10.00 & 7.00 & 6.00 & 6.00 & 7.600 & $b$ \\
\hline Wrapping & 7.00 & 8.50 & 5.50 & 5.50 & 4.50 & 6.200 & a \\
\hline RATAAN & 8.00 & 9.25 & 6.25 & 5.75 & 5.25 & & \\
\hline DUNCAN 5\% & b & $c$ & $a$ & a & a & & \\
\hline
\end{tabular}

Dari Tabel 5 terlihat bahwa total padatan terlarut menurun selama penyimpanan dari 8,00 Brix pada hari ke 0 , menjadi 5,25brix pada penyimpanan hari ke 4. Penurunan total padatan terlarut pada umumnya mengalami peningkatan selama penyimpanan berbeda dengan hasil penelitian ini yang mengalami penurunan. Sementara itu pada Tabel 5 terlihat bahwa penyimpana dengan plastik kemasan menghasilkan TSS lebih tinggi (7,60brix) dibandingkan dengan penyimpanan kemasan wrapping sebesar (6,20brix). Hal ini disebabkan bahwa pada kemasan plastik, penutupan kemasan tidak tertutup rapat sehingga oksigen yamg masuk ke dalam kemasan mempercepat proses respirasi yang memecah senyawa besar yang tidak larut seperti amilosa menjadi glukosa yang larut air. Semakin banyak glukosa yang dihasilkan maka TSS meningkat.

Pengaruh lama penyimpanan dan jenis kemasan terhadap uji kesukaan warna harimonting.

Lama penyimpanan memberi pengaruh nyata $(p>0,05)$ terhadap uji kesukaan warna, sedangkan jenis kemasan memberi pengaruh tidak nyata $(\mathrm{p}<0,05)$ seperti terlihat pada Tabel .6
Tabel 6. Pengaruh lama penyimpanan dan jenis kemasan terhadap uji kesukaan warna harimonting

\begin{tabular}{lccccc}
\hline \multirow{2}{*}{$\begin{array}{c}\text { Jenis } \\
\text { kempasan }\end{array}$} & 0 & 1 & 2 & 3 & 4 \\
\cline { 2 - 6 } Plastik & 2.80 & 3.30 & 2.90 & 3.25 & 3.10 \\
Wrapping & 3.15 & 3.35 & 2.20 & 3.40 & 3.60 \\
RATAAAN & 2.97 & 3.33 & 2.55 & 3.33 & 3.35 \\
DUNCAN 5\% & $\mathrm{ab}$ & $\mathrm{b}$ & $\mathrm{a}$ & $\mathrm{b}$ & $\mathrm{b}$ \\
\hline
\end{tabular}

Pada Tabel 6 terlihat bahwa ada kecendrungan kenaikan kesukaan warna dari 2,97 pada hari ke 0 (nol) menjadi 3,35 pada hari penyimpanan hari ke 4 . Warna hari monting tergantung kepada tingkat kematangan buah. Kepekatan Warna ungu meningkat hingga warna hampir hitam seiring dengan meningkatnya kematangan buah. Selama penyimpanan buah semakin matang dan warna semakin menarik karena ada variasi warna ungu dan warna hampir hitam pada buah harimonting.

Pengaruh lama penyimpanan dan jenis kemasan terhadap kadar vitamin $C$ harimonting.

Lama penyimpanan memberi pengaruh nyata $(p>0,05)$ terhadap kadar vitamin $\mathrm{C}$, sedangkan jenis kemasan memberi pengaruh tidak nyata $(p<0,05)$ seperti terlihat pada Tabel 7

Tabel 7. Pengaruh lama penyimpanan dan jenis kemasan terhadap kadar vitamin C (mg/100 g) harimonting.

\begin{tabular}{lccccc}
\hline & \multicolumn{5}{c}{ Lama penximpanan (hari) } \\
\cline { 2 - 6 } Jenis \\
\cline { 2 - 6 } kemasan & 0 & 1 & 2 & 3 & 4 \\
\hline Plartik & 40.84 & 42.24 & 33.44 & 36.08 & 23.76 \\
Wrapping & 45.04 & 37.68 & 30.11 & 27.98 & 20.68 \\
Rataan & 42.94 & 39.96 & 31.78 & 32.03 & 22.22 \\
Duncan 5\% & C & C & B & b & a \\
\hline
\end{tabular}

Pada Tabel 7 terlihat kadar vitamin C menurun dari $42,94 \mathrm{mg} / 100 \mathrm{~g}$ pada penyimpanan nol hari menjadi 22,22 mg/100g pada penyimpanan hari ke 4 . Penurunan kadar vitamn C selama penyimpanan disebabkan selama penyimpanan terjadi metabolism respirasi yang mengakibatkan perubahan senyawa kimia didalam buah harimonting. Seperti disebutkan (wills et al, 1981) Vitamin C mudah rusak karena proses oksidasi terutama pada suhu tinggi dan vitamin ini mudah hilang selama 
pengolahan dan penyimpanan bahkan disebutkan walaupun dalam keadaan temperatur rendah dan kelembaban terpelihara, $50 \%$ vitamin $\mathrm{C}$ akan hilang dalam 3-5 bulan. Penurunan vitamin C selama penyimpanan mengikuti garis regresi linier seperti terlihat pada Gambar 3

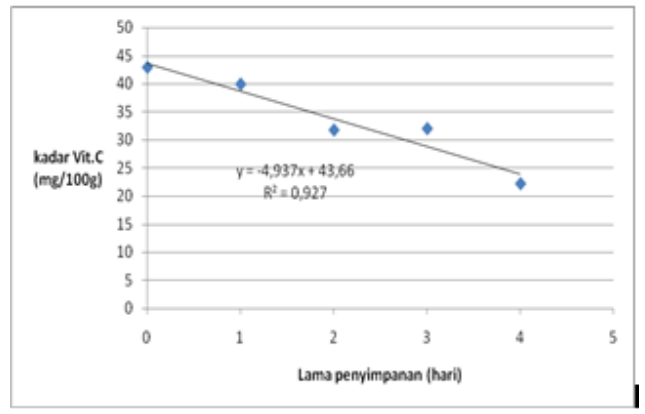

Gambar 3. Hubungan lama penyimpanan dengan kadar vit.C buah harimonting

\section{KESIMPULAN}

1. Kosentrasi antioksidan (IC 50 ) mengalami peningkatan selama penyimpanan dari 58,94 ppm pada nol hari menjadi 97,04ppm pada penyimpanan 4 hari dengan kemasan plastic dan dari 48,04ppm pada penyimpanan nol hari meningkat menjadi 92,94ppm dengan kemasan wrapping. Susut bobot dan TSS kemasan plastik lebih tinggi dibandingkan kemasan wrapping masing-masing dengan nilai $7,40 \%$ ) dengan $4,80 \%$ dan plastik 7,60brix dengan 6,20brix. Sedangkan uji warna dan kandungan vitamin C tidak dipengaruhi jenis kemasan.

2. Selama penyimpanan susut bobot meningkat dari $0,00 \%$ menjadi $11,48 \%$ dan nilai kesukaan warna dari 2,97 menjadi 3,35. Sedangkan total padatan terlarut menurun dari 8,00brix menjadi 5,25brix dan vitamin C menurun dari 42,94 $\mathrm{mg} / 100 \mathrm{~g}$ menjadi $22,22 \mathrm{mg} / 100 \mathrm{~g}$.

\section{SARAN}

Ditinjau dari parameter susut bobot dan TSS disarankan menggunakan kemasan wrapping dibandingakn dengan kemasan plastic, namun bila ditinjau dari parameter antioksidan disarankan menggunakan kemasan plastik. Lama penyimpanan paling lama 4 hari.

\section{DAFTAR PUSTAKA}

Harianja, A.H. 2016. Potensi ekonomi budidaya tanaman buah-buahan khas batak toba yang bersumber dari hutan di lagundi kabupaten samosir. Prosiding Seminar Nasional Inovasi dan Teknologi Informasi SNiTI-3.: 1634-1638.

Iflah, T., Sutrisno, dan Sunarti, T.C. 2012. Pengaruh kemasan starch-based plastics (bioplastik) terhadap mutu tomat dan paprika selama penyimpanan dingin. Jurnal Teknologi Industri Pertanian 22 (3):189-197.

Jumiati, E, Mardhiana, dan Abdiani, I. M. 2017. Pemanfaatan buah karumunting sebagai pewarna alami makanan. Jurnal AGRIFOR. Volume XVI Nomor 2: 163-170.

Mardawati, E., Achyar, C. S., dan Marta, H. 2008. Kajian aktivitas antioksidan ekstrak kulit Manggis (Garcinia mangostana L) dalam rangka pemanfaatan limbah kulit manggis di Kecamatan Puspahiang Kabupaten Tasikmalaya. Teknologi Industri, Universitas Pajajaran, Bandung

Marliana, Eva, 2012, Aktivitas Antioksidan Ekstrak Etanol Daun Andong (Cordyline fruticosa (L.) A. Cheval), Mulawarman Scientifie, Vol.11 No.1.

Naibaho, B. 2014. Penggunaan beberapa jenis kemasan untuk memperpanjang masa simpan buah jambu biji ( Psidium guajava L.). Wahana Inovasi Volume 3 No.1. :23-38

Prakash, A. 2001. Antioxidant activity. Medallion Laboratories: Analytical Progress Vol. 19 No 2: 1-4.

Ramadan, M. F dan Moersel, J. T. 2006. Screening of the antiradical action of vegetable oils. Journal of Food Composition and Analysis 19:838842.

Rifkowaty, E.E., Wardanu, A.P, dan Hastuti, N. D. 2018. Aktivitas antioksidan sirup buah karamunting (rhodomyrtus tomentosa) dengan variasi penambahan asam sitrat. Jurnal 
H. Manurung and R. Simanjuntak / Agrintech | Jurnal Teknologi Pangan dan Hasil Pertanian 2 (2) 2019, 55-60

Teknologi dan Industri Pertanian Indonesia. Vol.10 No. 1: 16-20

Redha, Abadi, 2010, Flavonoid: Struktur, Sifat Antioksidan dan Peranannya dalam Sistem Biologis, Jurnal Belian, Vol.9: 196-202.

Sari, E.R., Hilma, Cendrakasih, C.2018. Penentuan akativitas antioksidan ekstrak biji dan daging buah karamunting (Rhodomyrtus tomnetosa) menggunakan metode DPPH. SCIENTIA Vol 8 No.1:37-43

Silalahi, J. 2006. Makanan Fungsional. Kanisius, Yogyakarta.

Situmorang, R. dan Harianja A.H. 2014. Faktor-Faktor Yang Mempengaruhi Kearifan Lokal Pemanfaatan ObatObatan Tradisional Oleh Etnik Karo. Prosiding Ekspose Hasil-Hasil Penelitian BPK Aek Nauli. Medan.
Soekarto, S.T. $\quad$ 1985. Penilaian Organoleptik untuk Industri Pangan dan Hasil Pertanian". Bhatara Karya Aksara, Jakarta.

Sudarmadji, S., Bambang. H, dan Suhardi. 1987. Prosedur Analisa untuk Bahan Makanan dan Pertanian. Lyberty.

Trisnawati, W dan Rubiyo. 2004. Pengaruh penggunaan kemasan dan lama penyimpanan terhadap mutu buah salak bali. Jurnal Pengkajian dan Pengembangan Teknologi Pertanian Vol.7 No.1:7682

Wills, R.A.H., T.H. Lee, D. Graham, W.B. McGlasson, E.G. Hall. 1981. Postharvest An Introduction to the Physiology and Handling of Fruit and vegetables. New South Wales University Press. Sydney. 